\title{
Parental Awareness of Early Intervention for Hispanic Children with Communication Disorders
}

\author{
Ruth Crutchfield \\ University of Texas Rio Grande Valley, ruth.crutchfield@utrgv.edu \\ Sonya N. Salinas \\ University of Texas Rio Grande Valley, sonya.salinas@utrgv.edu \\ Roy K. Chen \\ University of Texas Rio Grande Valley, roy.chen@utrgv.edu
}

Follow this and additional works at: https://nsuworks.nova.edu/ijahsp

Part of the Communication Sciences and Disorders Commons, Community Health and Preventive Medicine Commons, and the Public Health Education and Promotion Commons

\section{Recommended Citation}

Crutchfield R, Salinas SN, Chen RK. Parental Awareness of Early Intervention for Hispanic Children with Communication Disorders. The Internet Journal of Allied Health Sciences and Practice. 2021 Jan 01;19(1), Article 19.

This Manuscript is brought to you for free and open access by the College of Health Care Sciences at NSUWorks. It has been accepted for inclusion in Internet Journal of Allied Health Sciences and Practice by an authorized editor of NSUWorks. For more information, please contact nsuworks@nova.edu. 


\title{
Parental Awareness of Early Intervention for Hispanic Children with Communication Disorders
}

\begin{abstract}
Purpose: Children at risk of delayed speech and language development and speech-language disorders come from a broad range of demographic backgrounds, including ethnicities, sexes, and socioeconomic statuses. A vast body of research in speech-language pathology has demonstrated that early intervention is crucial for helping children acquire the necessary communication skills they need to become effective communicators, successful students, and ultimately accomplished adults. Currently, commercials, billboards, online sources, and personal referrals are the methods most often used to promote awareness of early childhood intervention services. Method: This study aimed to identify whether the current promotional methods used to increase parental awareness of early childhood speech therapy intervention are effective in the Hispanic population in South Texas. A total of 299 parents and guardians recruited from 18 Head Start programs took part in the survey study. The 18-item Early Intervention Parental Awareness Questionnaire was utilized to assess the participants' level of awareness. Results: The results of this study suggest face-to-face interaction is needed to increase awareness of services for early childhood intervention amongst the Hispanic population. Conclusion: These findings support the need for increasing recognition of the value of early intervention for children with communication disorders amongst the Hispanic population.
\end{abstract}

\section{Author Bio(s)}

Ruth Crutchfield is an Associate Professor at the University of Texas Rio Grande Valley where she teaches graduate and undergraduate courses. She is the President of the Texas Organization of Multilingual and Multicultural Audiologists and Speech Language Pathologists.

Sonya N. Salinas, M.A., CCC-SLP is a Associate Clinical Professor at the University of Texas Rio Grande Valley. She is a Clinical Instructor/ Clinical Supervisor and the Undergraduate Program Coordinator in the Communication Sciences and Disorders Department.

Roy K. Chen, PhD, CRC, is a professor of rehabilitation counseling in the School of Rehabilitation Services and Counseling at the University of Texas Rio Grande Valley.

\section{Acknowledgements}

Acknowledgement Kayla Vanden Esschert and Jhordan Wynne University of Michigan, Ann Arbor 


\title{
IIAAHSP \\ The Internet Joumnal of Allied Health Sciences and Practice \\ Dedicated to allied health professional practice and education \\ Vol. 19 No. 1 ISSN 1540-580X
}

\section{Parental Awareness of Early Intervention for Hispanic Children with Communication Disorders}

\author{
Ruth Crutchfield \\ Sonya N. Salinas \\ Roy K. Chen \\ University of Texas Rio Grande Valley \\ United States
}

\begin{abstract}
Purpose: Children at risk of delayed speech and language development and speech-language disorders come from a broad range of demographic backgrounds, including ethnicities, sexes, and socioeconomic statuses. A vast body of research in speechlanguage pathology has demonstrated that early intervention is crucial for helping children acquire the necessary communication skills they need to become effective communicators, successful students, and ultimately accomplished adults. Currently, commercials, billboards, online sources, and personal referrals are the methods most often used to promote awareness of early childhood intervention services. Method: This study aimed to identify whether the current promotional methods used to increase parental awareness of early childhood speech therapy intervention are effective in the Hispanic population in South Texas. A total of 299 parents and guardians recruited from 18 Head Start programs took part in the survey study. The 18-item Early Intervention Parental Awareness Questionnaire was utilized to assess the participants' level of awareness. Results: The results of this study suggest face-to-face interaction is needed to increase awareness of services for early childhood intervention amongst the Hispanic population. Conclusion: These findings support the need for increasing recognition of the value of early intervention for children with communication disorders amongst the Hispanic population.
\end{abstract}

Keywords: parental awareness, speech-language services 


\section{INTRODUCTION}

Children who are at risk of a speech and language delay or a disorder come from different backgrounds, ethnicities, gender, and socioeconomic status. Past research has indicated that a significant number of American children have had some form of speech and language impairment. The prevalence of speech sound disorders is estimated to range from $2 \%$ to $25 \%$ in children aged 5 to $7 .{ }^{1}$ In a large-scale epidemiologic study of 7,218 children in urban, rural, and suburban areas in the upper Midwestern states to screen for specific language impairment, Tomblin et al (1997) found that the prevalence is $7.4 \%$ overall, $6 \%$ for girls and $8 \%$ for boys. Additionally, the prevalence of language disorders in racial/ethnic groups is highest amongst Native Americans, followed by African Americans, Hispanics, and European Americans. ${ }^{2}$ Research in the field of speech-language pathology has consistently demonstrated that early intervention is pivotal in helping these children acquire the communication skills needed to be effective communicators, successful students, and ultimately successful adults. Given that communication abilities impact all aspects of a person's development, including social interaction, learning, and self-esteem, it is imperative for rehabilitation professionals to provide services and therapies to children as soon as they are diagnosed with speech and language deficits.

Speech language disorders can affect individuals in many negative ways, including impeding communication, affecting school performance, and causing social distress. If there is a lack of intervention or late intervention, children may experience lifelong consequences. ${ }^{3}$ Under the Individuals with Disabilities Education Improvement Act of 2004, access to speech-language pathology services for preschool and school-aged children is mandated. ${ }^{4}$ However, many barriers exist that may prevent parents from accessing services for their children.5,6 First, parents must identify that their child has an impairment and must be concerned enough to seek help. Second, services must be accessible, and children must be receptive to receiving therapy. Overcoming barriers to early childhood interventions regarding speech-language pathology is essential to ensure children receive early treatment.

\section{BACKGROUND}

A review of three major databases, including ComDisDome, Ebsco Host, and JSTOR, and the American Speech-LanguageHearing Association (ASHA) Journals, was conducted. The search terms "parent awareness" and "early childhood intervention" were employed. The literature search revealed few controlled studies in the area of parental awareness of early childhood intervention in relation to speech-language pathology. The three relevant studies found reveal common themes highlighted in the available literature about early childhood intervention services-accessibility, physician referrals awareness, and media sources.

McAllister et al (2011) investigated accessibility to and parental engagement with speech-language pathology services in relation to Australian children. While many parents are concerned about their children's speech, only one third have attempted to access services for their child, with only $27 \%$ of these receiving interventions. Teachers, family/friends, and physicians are the most prevalent sources of information regarding their children's speech impairment.

Verdon et al highlighted the importance of geographic location in regard to accessing and utilizing speech-language pathology services. These authors investigated the disparities of speech-language pathology services in rural areas in Australia. ${ }^{5}$ The results showed that almost $99 \%$ of localities are underserviced as the ideal frequency of visits is once per week. Travel and distance were found to be barriers to accessibility. ${ }^{5}$

Reynolds, Ou, and Topitzes focused on the general impact of preschool participation at child-parent centers in Chicago. ${ }^{6}$ They concluded that preschool participation was associated with higher rates of educational attainment and lower rates of juvenile arrest. Although this investigation did not focus on the use of speech pathology services, it is important to note why early childhood interventions are important. Only three relevant studies were found regarding early childhood interventions about speech pathology services, highlighting the lack of research in this area. While there is literature on speech language disorders and early childhood interventions, the overlap in the literature is sparse.

\section{Awareness}

For parents to seek out services their children need, they first need to be aware that a problem may exist. Knowing what is developmentally appropriate in terms of speech is important in identifying when a child needs additional language supports. McAllister et al also noted that being aware of a problem is important. ${ }^{4}$ One noted theme is that parents waited for a teacher or pediatrician to notice the issue because they expect professionals to have greater knowledge of speech development. ${ }^{4}$ When parents are not aware of what qualifies as concerning behavior, children do not receive timely treatment. Children may also not receive needed therapies because their parents are not concerned about their speech development. ${ }^{4}$ Parents who do not see a problem are not going to seek out services. Increasing parental awareness not only of the services available but also of what signs to look for in their children will help more children receive timely speech and language intervention. 


\section{Physician Referral}

One issue McAllister et al addressed is physicians' attitudes regarding speech impairment. Speech language pathologists often report that their clients' general practitioners tell parents that children with speech problems will grow out of it. ${ }^{4}$ This is a common misconception, as many children continue to struggle with speech problems into adulthood. Short, Woolfenden, Blackmore, Best, and Croft found that the majority of general practitioners in Australia express a desire for more training to identify communication impairments in children. ${ }^{7}$ Additionally, general practitioners feel that waiting lists, availability of services, and cost are the main barriers in referring patients to speech services. Parents look to physicians as experts on a wide variety of health issues, and if physicians are not confident in referring patients for additional services, parents may not be reassured that speech-language services are necessary.

\section{Media Sources}

Another common source of referral is the media. ${ }^{4}$ Books, newspaper, magazines, television, videos, and the Internet are all ways that communication difficulties are advertised to parents. Many parents see advertisements and start to recognize these difficulties in their children and therefore seek services. According to McAllister et al, the Internet is the most common source of information about children's communication difficulties, followed by books, newspapers, and magazines. ${ }^{4}$ Media are an important way to communicate common health problems to the public and to advertise local resources/therapy to those in need.

\section{Accessibility}

Verdon et al discussed accessibility to resources and define it as the ability to utilize existing and available resources. ${ }^{5}$ Factors that impact accessibility to a health resource are travel parameters and frequency of service. The longer the travel time, the less accessible the resource becomes. The relationship between the frequency of use and travel time also plays a big role in accessibility. Verdon and colleagues argue that the more frequently a treatment or service is required, the less acceptable it is to travel far distances. McAllister et al also emphasizes distance as a barrier to receiving services. ${ }^{4}$ Families that do not live near speech therapy and rehabilitation sites cannot easily receive help for their children.

Verdon et al also discussed affordability as a barrier to accessibility. ${ }^{5}$ Reynolds et al suggested that the cost of receiving intervention or therapy limits who can access the resource. ${ }^{6}$ The authors state that cost prevent parents from accessing certain early childhood services/interventions in Chicago, Illinois. ${ }^{6}$ For services that require significant travel time, it is reasonable to assume that a vehicle or other reliable transportation is required. This further limits access for those who do not have ready, affordable transportation. In the survey conducted by McAllister et al, parents mention the cost of services as a barrier to their child receiving speech-language pathology services. ${ }^{6}$ It is important for speech-language services to be affordable so that families of all backgrounds and socioeconomic levels are able to access them.

Another accessibility issue is waitlists at rehabilitation facilities. Long waits for service are one of five barriers identified by parents in the study. ${ }^{4}$ Waitlists can be stressful for parents trying to provide their children with speech-language therapies. ${ }^{4}$ This accessibility issue has been emphasized along with transportation to therapy sites. Because there are few speech pathologists working in rural Australia, there is a large workload for each pathologist. These large workloads mean longer waitlists for services, a barrier that may deter parents from seeking services for their children.

\section{Generalizability}

Many studies in the literature, because of design methods and sample selection, allow the findings to be generalized to other populations. The survey of access to speech and language resources for rural communities by McAllister et al and the study by Verdon et al focusing on rural communities in Australia are of great relevance. ${ }^{4,5}$ Reynolds et al suggested using large organizations, such as Head Start programs, as a good way to sample a population because their participants represent the larger population. ${ }^{6}$ This is limiting, however, because it only represents lower income families. Administering early childhood interventions requires social support be in place to be most effective. ${ }^{6}$ Head Start and other similar organizations place value on parent involvement and provide their students with a social support system outside the home.

Although many aspects of the research by McAllister et al and Verdon et al are relevant, we must be cautious in any assumptions made regarding the generalizability of their findings. 4,5 Because both of these studies were conducted in rural Australia, we cannot assume that all findings can be translated into a US context. In addition, findings may differ if studies are conducted in urban areas. Taking into consideration the limitations to the generalizability of the given data, we can use the data to make hypotheses regarding patterns and trends in the US. 


\section{Literature Discussion}

After reviewing these studies, conclusions can be made about the importance of early childhood interventions in terms of speechlanguage services. As demonstrated in McAllister et al, it is difficult for parents to know the appropriate stage of speech and language development their children should be at. ${ }^{4}$ Therefore, they depend heavily on professionals such as teachers and general practitioners to inform them of any speech impairments their children may have. Recommendations have been made to provide training for these professionals to increase their competency in recognizing communication impairments in children. Both McAllister et al and Reynolds et al emphasized that early childhood interventions are essential to children's growth and development. ${ }^{4,6}$ It is important that speech-language pathology services are provided to children in need before the age of five so they can improve speech development before they reach an age when it is harder to change behavior.

The literature reviewed discusses the barriers to speech-language pathology services for children. Cost is a major barrier for many parents who may not have the monetary resources to pay for these services. In addition, transportation is a barrier that plays a role in accessing many health services. If there are no speech-language facilities relatively close to where people live, they may not be able to get the therapy their children need. Reynolds et al also investigated the availability of resources across urban and rural areas and concluded that the lack of services in rural areas and limited staff resources are structural barriers that affect who can access services. ${ }^{6}$

There is a lack of literature on early childhood speech-language services, which demonstrates the need for further research in this area. Additionally, the promotion of speech-language services in local communities is important to inform parents of the availability of these services for children with possible communication impairments. Early childhood speech-language development is an important part of children's overall growth and further research needs to be conducted to assess the barriers and gaps in providing these services to children in need.

The purpose of this study was to investigate parental awareness of early childhood intervention services available in the Rio Grande Valley, Texas for children who are at risk of delayed speech and language development. Specifically, the study attempted to identify whether the current promotional methods of increasing parental awareness of early childhood intervention in the form of speech therapy are effective among the Hispanic population. A close-ended questionnaire based on the reviewed literature was used to address the following research questions:

1. What factors impact access to early intervention speech language pathology services for the Hispanic population?

2. Do parents feel that early intervention services are beneficial?

3. What media sources do parents respond to when seeking referrals for early intervention speech language pathology services?

\section{METHODS}

\section{Participants}

The study participants were recruited from mainly Hispanic areas of south Texas along the Mexican border. ${ }^{8}$ The participants gave informed consent; however, all data was de-identified prior to performing data analysis. The survey questions were intended to determine the participants' awareness of the area of early childhood speech-language pathology and consisted of general demographic questions and awareness-related questions. Parents were asked if they have heard of early childhood speech therapy intervention and from what sources; if they have accessed early childhood speech therapy intervention and from which sources; if they feel the speech therapy program their children participated in was effective; and if they received training to improve their children's speech and language abilities in the home environment. The data was analyzed using descriptive statistics, measures of central tendency and item analysis.

\section{Instrument}

\section{Development of the Early Intervention Parental Awareness Questionnaire}

The investigative method for this study included quantitative research via a close-ended questionnaire, with one open question for comments at the end. ${ }^{9}$ The survey consisted of 18 items that utilized yes/no responses and questions requiring a Likert-type scale response as in the Early Intervention Parental Awareness Questionnaire. A Likert scale was selected as the main way of measuring attitudes because of its linearity. A close-ended method was selected to facilitate quantification and measurement. ${ }^{9}$ In researching previous literature on early intervention awareness, the findings revealed limited surveys relating to the focus population. The findings also revealed salient themes such as awareness, physician referral, media sources, accessibility, and generalizability. Based on these themes, survey questions were developed to answer the research questions.

\section{Procedure}


Head Start programs were visited for to administer the survey. A total of 13 Head Start programs were surveyed during a oneweek period when parents were attending national health week. The Head Start centers provided a schedule of events to the research team. The health fair event was chosen as the optimal time when a larger number of potential participants would be accessible. Parents at the event volunteered to participate in the survey, which was administered in the parents' preferred language (English or Spanish). Parents completed the survey either independently or verbally, with the research assistants writing down the parents' responses. The research assistants were integral to the completion of this project, as they assisted in organizing and implementing the questionnaire. Parents were asked to furnish demographic information such as race, age range, and sex. The survey contained an array of questions pertaining to speech-language pathology services for children aged 0-3 such as awareness of services, type of intervention their child was receiving, if any, the effectiveness of services and parent education.

\section{RESULTS}

A total of 299 participants took part in the present study. The majority of participants were female $(n=248,82.9 \%)$ and selfidentified as Hispanic $(n=287,90 \%)$. The largest age group was $26-35$ years old $(n=138,46.2 \%)$, followed by $36-45$ years old ( $n=72,24.1 \%), 18-25$ years old $(n=64,21.4 \%), 46-55$ years old $(n=15,5.0 \%)$, and $56-65$ years old $(n=5,1.7 \%)$. The questionnaires were available in both the English and Spanish languages. More than two-thirds of participants $(n=201,67.2 \%)$ filled out the surveys using the Spanish questionnaire and the remaining third preferred the English version $(n=98,32.8 \%)$. A majority of participants $(n=199,66.6 \%$ ) did not have a child who required speech-language services; however, slightly less than one-third of them $(n=91,30.4 \%)$ did. Nine participants $(3.0 \%)$ declined to report the need status of their child. Sixty-nine participants indicated that their child was currently receiving speech-language services. The average age of these 113 children (some families had multiple children with disabilities) was 4.15 years old ( $s d=2.045$ ), with a range from 1 to 14 years.

Table 1 displays a summary of responses to selected items of the questionnaire. Nearly eight out of ten of participants $(n=239$, $79.9 \%$ ) indicated that they were aware of speech-language pathology services for children ages $0-3$ offered by various agencies in their community. Head Start $(n=193)$ was by far the agency which was familiar to the most participants, followed by Public Schools $(n=79)$, Private Rehabilitation Centers $(n=63)$, Region One $(n=38)$, Easter Seals $(n=29)$, and Texas Migrant Council $(n=20)$. The most often cited reason as to why participants did not seek therapy for their children was a lack of information about services provided $(n=65,45.1 \%)$. Other deterrents included finances $(n=36,35.0 \%)$, transportation $(n=34,23.6 \%)$, and an unfavorable impression of the facility $(n=9,6.3 \%)$. For the 189 children who were currently receiving services, most of them obtained aid at Public Schools $(n=116,61.4 \%)$, followed by Private Rehabilitation Centers $(n=49,25.9 \%)$, and Other Facilities $(n=24,12.7 \%)$. Regarding the type of speech-language services the child was receiving, Individual $(n=76,62.8 \%)$ was the preferred treatment of choice, followed by Group $(n=41,33.9 \%)$ and Consultative $(n=4,3.3 \%)$.

Table 1: Summary of Responses to Selected Items of the Questionnaire

\begin{tabular}{|c|c|c|}
\hline \multicolumn{1}{|c|}{ Issue } & Total & Percentage \\
\hline Awareness of the existing agencies & 20 & 4.7 \\
\hline Texas Migrant Council & 193 & 45.5 \\
\hline Head Start & 39 & 9.2 \\
\hline Region One & 30 & 7.1 \\
\hline Easter Seals & 63 & 14.9 \\
\hline Private Rehabilitation Centers & 79 & 18.6 \\
\hline Public Schools & $424^{*}$ & $100 \%$ \\
\hline Reasons deterred from seeking services & & \\
\hline Finances & 36 & 35.0 \\
\hline Transportation & 34 & 23.6 \\
\hline Lack of information & 65 & 45.1 \\
\hline Unfavorable impression of the facility & 9 & 6.3 \\
\hline & 144 & $100 \%$ \\
\hline Level of comfort in seeking services & & 4.5 \\
\hline Not comfortable & 10 & 10.9 \\
\hline Somewhat comfortable & 24 & 52.0 \\
\hline Comfortable & 115 & 32.6 \\
\hline Very comfortable & 72 & $100 \%$ \\
\hline Perceived effectiveness of therapy & 221 & \\
\hline TOLS & & \\
\hline
\end{tabular}




\begin{tabular}{|l|c|c|}
\hline Not effective & 6 & 4.5 \\
\hline Somewhat effective & 22 & 16.3 \\
\hline Effective & 52 & 38.5 \\
\hline Very effective & 55 & 40.7 \\
\hline Tovel of comfort in implementing therapy ideas in home & 135 & $100 \%$ \\
\hline Not comfortable & & \\
\hline Somewhat comfortable & 10 & 8.5 \\
\hline Comfortable & 9 & 7.6 \\
\hline Very comfortable & 65 & 55.1 \\
\hline & 34 & 28.8 \\
\hline
\end{tabular}

Note. ${ }^{*}$ The total number of choices exceeded the total number of respondents because they were allowed to report multiple locations.

A one-item, four-point Likert-type scale, ranging from $1=$ Not comfortable, $2=$ Somewhat comfortable, $3=$ Comfortable, to $4=$ Very comfortable, was used to assess the levels of comfort among participants in seeking services for their children from the agencies. The average score was $3.13(s d=.776)$ out of 221 respondents. The category of Comfortable accounted for $52.0 \%(n$ $=115$ ) of all responses. A one-item, four-point Likert-type scale, ranging from $1=$ Not effective, $2=$ Somewhat effective, $3=$ Effective, to $4=$ Very effective, was used to assess the perceived effectiveness of therapy in increasing a child's speech-language skills among participants. The average score was $3.16(s d=.854)$ out of 135 responses. The category of Very effective accounted for $40.7 \%(n=55)$ of all responses.

Almost $60 \%$ of 197 respondents revealed that they were not receiving parent education regarding how to generalize therapy ideas in the home setting for their child. When asked about where they obtained parent education, $44(47.8 \%)$ respondents indicated Public Schools. Two groups of $24(26.1 \%)$ respondents each received their information from Private Rehabilitation Centers and Other Facilities, respectively. A one-item, four-point Likert-type scale, ranging from $1=$ Not comfortable, 2 = Somewhat comfortable, $3=$ Comfortable, to $4=$ Very comfortable, was used to assess the levels of comfort among parents/guardians in implementing in their home those therapy ideas which they had learned from professionals. The average score was $3.04(s d=.841)$ out of 118 responses. The category of Comfortable accounted for $55.1 \%(n=65)$ of all responses.

Table 2 shows how parents/guardians heard about speech-language pathology services. More participants $(n=180)$ had heard of Head Start than of any other agencies. The second most familiar agency was Public Schools $(n=99)$, followed by Private Rehabilitation Centers $(n=84)$, Region One $(n=58)$, Texas Migrant Council $(n=56)$ and Easter Seals $(n=38)$. Collectively, the most effective way for all agencies to share information on services in the community was via word of mouth by Friends $(n=307$, $59.6 \%)$. In contrast, dissemination of therapy information via Online seemed to reach the fewest participants $(n=47,9.1 \%)$. For example, participants who came to know of speech-language pathology services offered in Public Schools were most likely to have done so through word of mouth by Friends $(n=57,57.6 \%)$, followed by Billboards $(n=19,19.2 \%)$, Commercial $(n=13,13.1 \%)$ and Online $(n=10,10.1 \%)$.

Table 2: Summary of How Parents/Guardians Heard About Agencies

\begin{tabular}{lccccccccc}
\hline \multicolumn{1}{c}{ Agency } & \multicolumn{1}{c}{ Commercial } & \multicolumn{2}{c}{ Billboards } & \multicolumn{2}{c}{ Online } & \multicolumn{3}{c}{ Friend } & Total \\
& $n$ & $\%$ & $n$ & $\%$ & $n$ & $\%$ & $n$ & $\%$ & \\
\hline Texas Migrant Council & 13 & $23.2 \%$ & 9 & $16.1 \%$ & 4 & $7.1 \%$ & 30 & $53.6 \%$ & 56 \\
Head Start & 9 & $5.0 \%$ & 31 & $17.2 \%$ & 13 & $7.2 \%$ & 127 & $70.6 \%$ & 180 \\
Region One & 9 & $15.6 \%$ & 11 & $18.9 \%$ & 7 & $12.1 \%$ & 31 & $53.4 \%$ & 58 \\
Easter Seals & 8 & $21.1 \%$ & 6 & $15.8 \%$ & 2 & $5.2 \%$ & 22 & $57.9 \%$ & 38 \\
Private Rehabilitation Centers & 17 & $20.2 \%$ & 16 & $19.0 \%$ & 11 & $13.1 \%$ & 40 & $47.6 \%$ & 84 \\
Public Schools & 13 & $13.1 \%$ & 19 & $19.2 \%$ & 10 & $10.1 \%$ & 57 & $57.6 \%$ & 99 \\
Total & 69 & $13.4 \%$ & 92 & $17.9 \%$ & 47 & $9.1 \%$ & 307 & $59.6 \%$ & 515 \\
\hline
\end{tabular}

Note. Some percentages did not add up to 100 due to rounding off at the two-decimal significant digits.

After independently reading the participants' written comments on speech-language pathology services, the first three authors developed a list of keywords to further analyze the contents in the transcripts. Those authors compared their notes constantly and coded them accordingly to create new domains. ${ }^{10}$ Based on the observation of recurrent concerns and thoughts expressed by the participants, one important theme emerged from the data: Services are beneficial. 


\section{Services are Beneficial}

Many parents and guardians observed significant improvements in the development of speech and language skills in their youngsters. Participant \#R013 (Hispanic female) wrote:

"My son really became more productive in his speech thanks to Headstart. He had an extremely limited vocabulary by 2 $1 / 2$ years. He was very far behind on his age group as far as speech development was concerned. Thanks to 2 years of Headstart, he is now one of the most productive 3rd graders in his class."

Several participants echoed similar sentiments. Participant \#R085 (Hispanic female) wrote:

"Excellent therapists. I noticed a great advance in her [daughter's] personal development when she was able to communicate more easily."

Participant \#161 (Hispanic female) was very pleased with the therapy results:

"I am very happy with the Head Start program because my daughter has learned a lot and continues to learn."

Participant \#R232 (Hispanic male) concurred:

"My child is good progression, thanks to all the people that take their time to teach my child to speak."

\section{DISCUSSION}

The purpose of the present study was to identify the level of awareness of parents and caregivers regarding early childhood intervention services specific to speech-language pathology in the Rio Grande Valley, Texas. The survey findings paralleled the findings of previous literature in multiple ways. McAllister et al identified the importance of awareness. ${ }^{4}$ For parents to seek out services their children need, they first must be aware that a problem may exist. The present study revealed that parents understand that intervention is beneficial Their awareness of the need for intervention is documented by the survey responses. McAllister et al identified media sources as a common source promoting referral due to in the way the information is shared. ${ }^{4}$ The present study illuminated the use of billboards as a media source in addition to the use of books, newspapers, magazines, television, videos, and the Internet. In contrast to past research that identified accessibility as a factor that impacted health resources (travel parameters and frequency of service), this study identified the availability of information as the main factor directly related to accessibility. $4,6,5$ Finances were identified as the second most common deterrent, followed by transportation.

\section{Implications}

The results of this study provide information regarding the need for face-to-face interaction to increase awareness of services for early childhood intervention amongst the Hispanic population. Hispanic parents were found to be more receptive to receiving recommendations for services for their children when the sources of referral are individuals (i.e. friends, family, acquaintances) they are comfortable with because of the interactions they have had in their community. This indicates that increased efforts must be made in the area of community events and community outreach where the sources of referral physically enter the community to promote awareness of services in a consistent manner. When addressing media sources, the use of billboards for advertisement was the second most common source of promoting early intervention. Ultimately, the surveyed parents felt early intervention is beneficial for their children, thus demonstrating the need for early awareness to optimize access to early intervention.

\section{Limitations}

The generalizability of the results is constrained by a few factors. First, the present study focused on surveying parents of children living in an overwhelmingly Hispanic region of south Texas. Therefore, the parents surveyed were mainly of Mexican American origin. Second, the Head Start centers were unable to provide the researchers with an allotted time for focused survey activity. The research team approached parents to ask their participation as they were attending a sponsored event or as they were dropping off their children. The hurried nature of these interactions might have influenced parents' willingness to participate and their responses. The small number of male parents in the sample is also a limitation, as the findings revealed that fathers have a different area of concern compared to mothers. The fathers surveyed identified transportation and finances as the main concerns when accessing early intervention. It would have been beneficial to obtain a larger male participant sample to clarify whether this concern is widespread.

\section{Future Research}

Considering the positive results of this study, it would be beneficial to replicate this survey of parents of Hispanic populations on a larger scale to determine whether our findings can be generalized to other US regions. In addition, changing the demographics to include specific ages will provide future researchers with data on the effect of generation and parental practice. 


\section{CONCLUSION}

The findings of this study support the need for increasing recognition of the value of early intervention for children with communication disorders amongst the Hispanic population. Face-to-face interaction is needed to increase awareness of services for early childhood intervention amongst the Hispanic population.

\section{References}

1. Law, J., Boyle, J., Harris, F., Harkness, A., \& Nye, C. Prevalence and natural history of primary speech and language delay: Findings from a systematic review of the literature. Int J Lang Commun Disord, 2000; 35(2):165-188.

2. Tomblin, J. B., Records, N. L., Buckwalter, P., Zhang, X., Smith, E. and O'Brien, M. Prevalence of specific language impairment in kindergarten children. J Speech Lang Hear Res, 1997; 40(6);1245-1260. PMID: 9430746.

3. U.S. Department of Education. Individuals with Disabilities Education Improvement Act of 2004. Washington, D.C; 2004.

4. McAllister, L., McCormack, J., McLeod, S., \& Harrison, L. J. Expectations and experiences of accessing and participating in services for childhood speech impairment. Int J Speech Lang Pathol, 2011;13(3):251-267. doi: 10.3109/17549507.2011.535565

5. Verdon, S., Wilson, L., Smith-Tamaray, M., \& McAllister, L. An Investigation of equity of rural speech-language pathology services for children: A geographic perspective. Int J Speech Lang Pathol, 2011; 13(3): 239-250. doi: 10.3109/17549507.2011.573865

6. Reynolds, A. J., Ou, S., \& Topitzes, J. W. Paths of effects of early childhood intervention on educational attainment and delinquency: A confirmatory analysis of the Chicago Child-Parent Centers. Child Dev, 2004; 75(5): 1299-1328.

7. Short, K., Woolfenden, S., Blackmore, R., Best, A., \& Croft, T. How do GPs identify and manage communication impairment in 0-5-year-old children? Speech Pathology Australia National Conference, Melbourne. 2010.

8. U.S. Census Bureau. QuickFacts: Texas. 2016 https://www.census.gov/quickfacts/TX

9. Gall, M. D., Gall J. P., \& Borg, W. R. (2003). Education research: An introduction (7th ed.). Boston, MA: Allyn and Bacon.

10. Hill, C. E., Thompson, B. J., \& Williams, E. N. A guide to conducting consensual qualitative research. Couns Psychol, 1997; 25(4): 517-572. doi: 10.1177/0011000097254001 